\title{
Double Barreled Questions: An Analysis of the Similarity of Elements and Effects on Measurement Quality
}

\author{
Natalja Menold ${ }^{1}$
}

\begin{abstract}
In double barreled questions (DBQs) respondents provide one answer to two questions. Assumptions how respondents treat DBQs and how DBQs impact measurement quality are tested in two randomized experiments. DBQs are compared with revisions in which one stimulus was retained while the other stimulus was skipped. The observed means and parameters when modeling latent variables differed among the versions. Metric and scalar measurement invariance was not given among the versions, and at least one single stimulus version was found to be associated with a higher validity. Response latencies did not differ among versions or respondents needed less time to respond to DBQs. The author concludes that respondents may understand the stimuli in a DBQ differently, and access one of them while disregarding the other, which can have an adverse effect on validity.
\end{abstract}

Key words: Question wording; double barreled questions; validity; comparability; measurement invariance.

\section{Introduction}

The recommendation to avoid double-barreled questions (DBQs) has been repeated in various textbooks (e.g., Bradburn et al. 2004; Dillman et al. 2014; Le Payne 1951; Oppenheim 1992) since the earliest days of survey research in the 1940s. DBQs present more than one aspect, such as opinions or behaviors, together in a single question so that "respondents must answer two questions with one answer" (Bradburn et al. 2004, 142).

Nonethless, despite recommendations to the contrary, DBQs remain very common in surveys and inventories. The question in the European Social Survey (ESS 2014) on media use, for example, requires respondents to evaluate two or more objects in a single question: "And again, on an average weekday, how much of your time watching television is spent watching news or programs about politics and current affairs?". Respondents have to estimate the amount of time they spend watching programs about politics - the first stimulus - and current affairs - the second stimulus. Further examples can be found in established inventories. The PVQ, Portrait Values Questionnaire (Schwartz 2003, 286), which is also included in the ESS and other large-scale surveys (e.g., GESIS-Panel), consists of questions containing at least two stimuli, each as a sentence: "How much are you like this person? He/she believes that people should do what they're told. He/she thinks people should follow rules at all times, even when no-one is watching."

1 Institute of Sociology, Technische Universität Dresden, D-01062 Dresden, Germany. Email: natalja.menold@tu-dresden.de 
Including more than one stimulus in a single question increases the question's complexity, which the survey research literature (e.g., Dillman et al. 2014) demonstrates is an undesirable property. Complexity may be associated with ambiguous and complex linguistic and grammar structures, such as the use of vague and imprecise terms (Graesser 2006; Lenzner et al. 2010), by the number of clauses (Yan and Tourangeau 2008), but also solely by the number of words and the number of syllables (Le Payne 1951). The complexity of survey questions, of which DBQs are a special instance, might increase cognitive burden for respondents so that they also take longer to respond to them (Lenzner et al. 2010). However, as Lenzner et al. (2010) discuss, we understand very little about what makes a question difficult or what imposes a cognitive burden. Likewise, although many authors expect DBQs to be associated with high cognitive burden and lower data quality (Dillman et al. 2014; Le Payne 1951; Oppenheim 1992), little is known about how DBQs impact the cognitive response process and measurement quality. With a focus on measurement of opinions in multi-item inventories, the present article describes experimental studies that investigate (1) how respondents respond to the stimuli in DBQs and (2) the impact of DBQs on response time and the quality of measurement of latent variables. The author formulates research hypotheses in the next two sections based upon the discussion of complexity of survey requests and respondents' cognitive process associated with DBQs. The author goes to describe the method and data of experimental studies and their results. Finally, discussion of the results and implications from the study are provided.

\subsection{Complexity Associated With DBQs}

The complexity of DBQs concerns two aspects: i) the wording of a question and ii) the cognitive process, which the complexity elicits in respondents. With respect to question wording, DBQs are linguistically more complex than analogous questions that contain just single stimuli (Single Stimulus Questions, SSQs). DBQs that form part of an independent sentence or a dependent clause in a complex sentence are themselves less complex. In such sentences, DBQs have every grammatical function that a word takes in a sentence: double subjects, activities, objects or those attributes. More complex, however, is the case of DBQs that consist of two (or even more) single sentences (sentences which may themselves be simple or complex), such as those of PVQ.

How does the cognitive process involved in responding to numerous stimuli differ from the process of responding to questions with one single stimulus? In contrast to SSQs, DBQs require an evaluative single response to two (or more) potentially different aspects (Oppenheim 1992; Le Payne 1951). This means that the cognitive process involved in responding to a DBQ, described by Tourangeau et al. (2000) as consisting of steps (1) comprehension, (2) retrieval, (3) judgement and (4) response, differs from the process of responding to a complex question that is not a DBQ. If a question is complex, but does not contain two or more stimuli for evaluation, respondents have difficulties at the comprehension stage in particular. However, in the case of a DBQ, if we assume a complex SSQ and a DBQ to be comparable in terms of complexity, respondents have to complete an additional task at the stage of comprehension, namely evaluate whether the two stimuli are similar or different in meaning. In the case of a complex SSQ, complexity 
may not itself effect retrieval and judgement. Once respondents have understood the question (although not without difficulties), they can retrieve and use memory information to respond to the question in the same way as they would to an easy question. Retrieval and judgement are more complex for DBQs than for SSQs, as for DBQs, respondents have to remember information und use it to form a response to each of the stimuli. If respondents evaluate the stimuli as similar, they can then arrive at a compound response for both stimuli. If they evaluate the stimuli to be different in meaning, it is more difficult or even impossible to generate a compound of such two stimuli, which reflects the high level of complexity of the respondents' cognitive task.

Some authors, for example, Bradburn et al. (2004, 142), discuss questions of the type "Are you in favor of building more nuclear power plants so that we can have enough electricity to meet the country's needs, or are you opposed to more nuclear power plants even though this would mean less electricity", as well as the attribution of attitudes to wellknown persons as double-barreled. However, other authors do not classify such questions as DBQs, but as “presuppositions" (Kay and Fillmore 1999; Dillman et al. 2014). Although presuppositions consist of different parts, like DBQs, they are distinct from DBQs in an important way. DBQs are questions that contain either specifications or features of one object, subject, or activity, or are grammatically independent enumerations of distinct objects, subjects, activities, and so on. There is a relationship of grammatical dependence between stimuli in a presupposition, as the stimuli either present a source and its effect, for example, or one barrel is object, subject, or activity while the other represents an attribute given to it. In a DBQ, each aspect should be responded to. By way of contrast, one of the barrels in a presupposition is the subject of evaluation, whilst the other represents facts or beliefs that are taken for granted (Kay and Fillmore 1999). The above example by Bradburn et al. (2004) takes it as given that more electricity can be generated with nuclear power plants (and in addition that this will enable the country to meet its needs). Respondents are assumed to be in agreement with premises that may in fact be wrong. The cognitive process for dealing with a presupposition would be even more complex than for dealing with a DBQ. When dealing with a presupposition, respondents do not evaluate the similarity or difference of stimuli at the comprehension stage, but have to decide about their agreement with the granted part at the judgement stage. Dillman et al. (2014) classify presuppositions differently from DBQs as questions that do not apply to every respondent. Similarly, the present article understands DBQs to be distinct from presuppositions. The author also avoids mixing questions with multiple stimuli that are connected with "and" and "or". Although questions with "or" could be seen as a special form of DBQs, the cognitive process may be different because respondents have to select a stimulus and can disregard the other. In the case of "and" and similar DBQ constructions, such a choice is not offered from the outset. Therefore, the present research does not address both presuppositions and double stimuli connected with "or".

If the task of respondents is difficult and their motivation or cognitive abilities are low, respondents might lean to satisficing behavior (e.g., Krosnick 1991; Krosnick and Presser 2009). Satisficing means that respondents who decide that the stimuli in a DBQ are different may just focus on one of them and disregard the other. It is also likely that respondents would even stop evaluating the similarity of two stimuli and pay attention to only one of them. 
As mentioned before, the common argument against DBQs is that respondents would be too confused to provide a response to two parts with different meanings. However, as empirical research on DBQs is rare, the cognitive process or the difficulties that respondents might have with them are not well understood. For example, we do not know what stimuli are evaluated by respondents as similar or different or in what cases. Research on this question is important because researchers who use DBQs in their inventories will have assumed that they transport similar meaning or that they are two parts of a compound entity (as otherwise they would have avoided posting ambiguous questions). The assumption that different stimuli in a DBQ would complement each other may be erroneous, as a study by Grant Levy (2019) demonstrates. In a randomized experiment with university students, Grant Levy (2019) compared the complex response alternatives (question from a GALLUP survey) with separate responses to each of the stimuli. The respondents' task was to "Circle the number that represents the statement that is closest to your belief" (Grant Levy 2019, 1996). In the first experimental condition, statements such as "God created human beings pretty much in their present form at one time within the last 10,000 years or so" were used. In the other condition, respondents had to evaluate separately: "How long do you believe human beings have been on the planet in approximately their present physical form? (a) About 5000 years ago (b) About 10,000 years ago (c) About 50,000 years ago (d) About 250,000 years ago" and "Do you believe that humans were created by God either through an evolutionary process or otherwise? (a) Yes (b) No". Grant Levy (2019) found very little correspondence between the conditions. This means that only a small proportion of the respondents selected response combinations that resembled the presented double-barreled version, that is (b) from the first question and (a) from the second question. The findings by Grant Levy (2019) therefore support the assumption that respondents can evaluate the stimuli included in a DBQ differently. Vettehen and Van Snippenburg (2002) evaluated questions of the kind "I watch television to keep up with important events". The authors showed that increasing the number of items that describe theoretically distinct motivations to watch television increased the correlation of the battery with the behavior "watching television." Since the common part of the motivation items and the behavior items was "watching television" and not the specific reason for this, the authors concluded that respondents tend to focus on the first part of the question "I watch television" and not on the specific motivation statement. Although the questions evaluated by Vettehen and Van Snippenburg (2002) would not necessarily be DBQs as defined here, the study provides evidence that in a complex question, respondents might consider only one part of a question and disregard the other.

The question arises as to how respondents treat more typical double-barreled opinion questions that were of present concern, such as "The age in which discipline and obedience to authority are some of the most important virtues should be over" (Aichholzer and Zeglovits 2015). Do the respondents agree that both, "discipline" and "obedience to authority", are not important virtues anymore, or would they think that this applies to the "obedience to authority" and not to "discipline"? Likewise, a respondent can feel herself less similar to a person who "believes that people should do what they're told" and more similar to someone who "thinks people should follow rules at all times, even when no-one is watching." If respondents respond comparably to both stimuli, such stimuli are referred to as similar or parallel. If the responses to the stimuli are not comparable, the stimuli are 
referred to as different and therefore non-parallel. In line with the rarely tested assumption in textbooks that respondents may evaluate the stimuli differently and therefore have difficulties responding to a DBQ (e.g., Oppenheim 1992) and in the light of the findings by Grant Levy (2019), the first hypothesis is stated as follows:

Hypothesis 1(H1): The single stimuli in DBQs have a different meaning to respondents and are therefore not parallel.

The present article focuses on opinion questions in multi-item instruments that have a desirable property to measure a latent concept or variable of interest, for example "Tradition" as human value in the case of PVQ. As compared to the study by Grant Levy (2019), scalar multi-item measures, that is, established inventories, are used. DBQs in scalar questions on opinions can be split into their separate parts and presented to different independent and randomly divided groups of respondents (Bassili and Scott 1996). To evaluate the degree of parallelism between the stimuli of a DBQ, one can compare manifest means between the groups, as well as measurement invariance (Meredith 1993) by means of LVM, Latent Variable Modeling (Raykov and Marcoulides 2011). Different understandings of stimuli in particular can be investigated by means of measurement invariance analysis when randomly divided groups of respondents evaluate them independently from each other (Hox et al. 2015).

\subsection{Effects of $D B Q s$}

Linguistically difficult questions were found to be associated with longer response times (Lenzner et al. 2010) or with higher context effects, such as effects of response options (Bless et al. 1992; Le Payne 1951). Some indications that DBQs negatively impact the response process, that is, that respondents have difficulties responding to them as outlined above, come from qualitative cognitive pretesting studies (e.g., Lenzner et al. 2017; Yorkston et al. 2008). It is not clear from these studies, however, whether the revised questions (with one stimulus) are easier to respond to and are thus associated with a higher measurement quality. Some inventory construction studies that document the item revision process provide support for the view that removing or revising DBQs can lead to higher measurement quality. These studies show that the measurement quality of forms that included DBQs and other problematic questions (negatives, double negations, etc.) was improved following a revision (e.g., Campbell et al. 2009; Fowler Jr. 1992; Gemenis 2013, Stafford 2011; Williams et al. 2009). However, many additional revisions beyond addressing DBQs were incorporated, so the improved measurement quality could be due to the removal of DBQs or also to other revisions.

Only a few studies focus on the impact of DBQs on data quality. After a systematic literature search, the author was only able to identify two publications by Borgers and Hox (2001) and by Bassili and Scott (1996). In their non-experimental correlative study on children, Borgers and Hox (2001) could not find any effects of DBQs on item nonresponse and suggested that experimental research on this topic should be conducted. However, in this article it remains unclear what kind of questions are classified as DBQs. Bassili and Scott (1996) compared DBQs with two versions in which the DBQs were split into separate parts using a telephone survey on a students' sample. (Each barrel in the study also contained presuppositions, but the authors split the barrels so that an SSQ was also a presupposition). Respondents experienced more difficulties with the DBQs than with the separated parts because the response latencies 
and the number of clarifications that respondents requested from an interviewer were higher for the original DBQ versions than for their parts, evaluated separately.

In line with the findings by Lenzner et al. (2010) and Bassili and Scott (1996), the author of the present study expected respondents' cognitive process to be of a greater difficulty in the case of inventories with DBQs than in the case of SSQs. Respondents would consequently need more time to respond to the DBQs than to the analogous questions with single stimuli. This issue is addressed by Hypothesis 2 .

Hypothesis 2 (H2): Response times are higher for inventories that include DBQs than for those with single stimuli.

In light of the above discussion about the potential satisficing in response to high-task difficulty, however, higher response times in the case of DBQs are plausible only if respondents carefully process information and spend effort in comprehension, retrieval and judgement.

With respect to complex and ambiguous questions, researchers report negative effects on measurement quality in terms of item nonresponse or evaluations of the effects of questionnaire properties, that is, rating scales or other context effects (e.g., Schaeffer and Dykema 2011). However, previous research has seldom addressed more direct metrics of measurement quality, such as reliability and validity (Schaeffer and Dykema 2011). The author assumes that the effect of DBQs would depend on the parallelism of stimuli in a DBQ with respect to their meaning and use. If stimuli in inventories with DBQs are parallel in meaning, there would not be differences between corresponding inventories with SSQs with respect to the results they provide, which also implies that there would be no differences between them in measurement properties. Therefore, in such a case, inventories with DBQs would not have lower reliabilities and validities than those with SSQs. However, if respondents evaluate the stimuli in DBQs as different and thus as not parallel, this would have a negative effect on data quality, i.e., on non-systematic measurement error or reliability as well as on systematic measurement error or validity (Groves et al. 2009). For the present study, a negative impact of DBQs on measurement quality is assumed as follows.

Hypothesis 3 (H3): Measurement quality (reliability and validity) is higher in inventories with SSQs than those with DBQs.

\section{Method and Data}

\subsection{Instruments}

The author conducted two independent, between-group-design experiments using two established inventories that employed DBQs: (1) a German language measure of authoritarianism, the Balanced Short Scale of Authoritarian Opinions (B-RWA-6) (Aichholzer and Zeglovits 2015) in the first experiment and (2) two subscales of PVQ (Schwartz 2003) in the second experiment.

The implementation of these instruments is of advantage, because they are based on established theories and are well documented with respect to the underlying concepts, measurement structure and measurement quality. This allows theoretically justified and empirically proven assumptions to be made about the properties of measurement (i.e., 
factorial structure, reliability and validity), as well as comparisons of measurements among different question wording forms.

To compare these original DBQ inventories with the use of a reduced number of stimuli, the author implemented two versions with SSQs that contained either one or the other stimulus. This resulted in three randomized groups in each experiment: (1) DBQ version (DBQ group), and two groups with single stimuli versions (2) SSQ1 group and (3) SSQ2 group.

The B-RWA-6 contains six items measuring three conceptual sub-dimensions of authoritarianism. Authoritarianism means support for authorities, being in favor of sanctions in the case of non-conformity, and rigid orientation towards traditions and established norms (Altemeyer 1981). The three sub-dimensions are "authoritarian submission", "authoritarian aggression" and "authoritarian conventionalism". Each sub-dimension consists of two items, one is positively worded, while the other is reversed (balanced scales).

In DBQ questions, which are of interest in the present article, double stimuli are enumerations in a sentence or grammatically independent sentences. DBQs included in a sentence contain multiple stimuli as enumerations, separated by comma or conjunction "and". A question can be a clause with the structure "subject (a man) + verb (reads) + object (a book)". Double stimuli would be two (or more) subjects, activities and objects. In more complex structures, an attribute can be added to each component: "a young man"; "reads with interest"; "a book about politics". Double stimuli can exist for such attributes as well. Similarly, double stimuli can be included in the subordinate clauses.

In the B-RWA-6 inventory, four items of six are double-barreled (sub-scale A "Submission" and B "Conventionalism"). Table 1 provides an overview of the wording of the items of the B-RWA-6 and their pertinent labels, AUT1 to AUT6. The double stimuli in the B-RWA-6 are components of independent and/or subordinate clauses. For example, let us look at the first item of the "Submission" sub-dimension (AUT1): "We should be grateful for leaders who tell us exactly what we shall do and how." In this item, "What" (we shall do) is the first and "How" is the second stimulus. If we look at the structure of the sentence, double stimuli are components of the subordinate clause and represent an object and an attribute of the verb "shall do". In the item AUT2 double stimuli are two subjects, and in the item AUT5 they are two objects, included in the subordinate clause. In AUT6, there are two verbs that describe the activity of the subject (people) in the subordinate clause as well.

The four items with double stimuli were reworded to obtain a single stimulus version. For example, for the item AUT1, one form (SSQ1 group) contained only the stimulus "What we shall do", while the second stimulus "How" was dropped resulting in the wording "We should be grateful for leaders who tell us exactly what we shall do". The wording of the other counterpart (SSQ2 group) was "We should be grateful for leaders who tell us exactly how we shall do something" (Table 1). To attain to the possible presentation order effects of the double stimuli in the original version, the author implemented a mixed order of the stimuli in the revised versions. So for the items AUT2 and AUT5 (Table 1), the second stimulus of the original DBQ was implemented in the SSQ1 version and the first stimulus of the original DBQ in the SSQ2 version. For the two remaining items (AUT1, AUT6) the SSQ1 version contained the first, and the SSQ2 version contained the second double stimulus. The items of the sub-dimension B "Aggression" (AUT3 and AUT4) did not contain double stimuli, so each experimental group used them without variations. The response formats also did not vary between the experimental groups (see Notes, Table 1). 


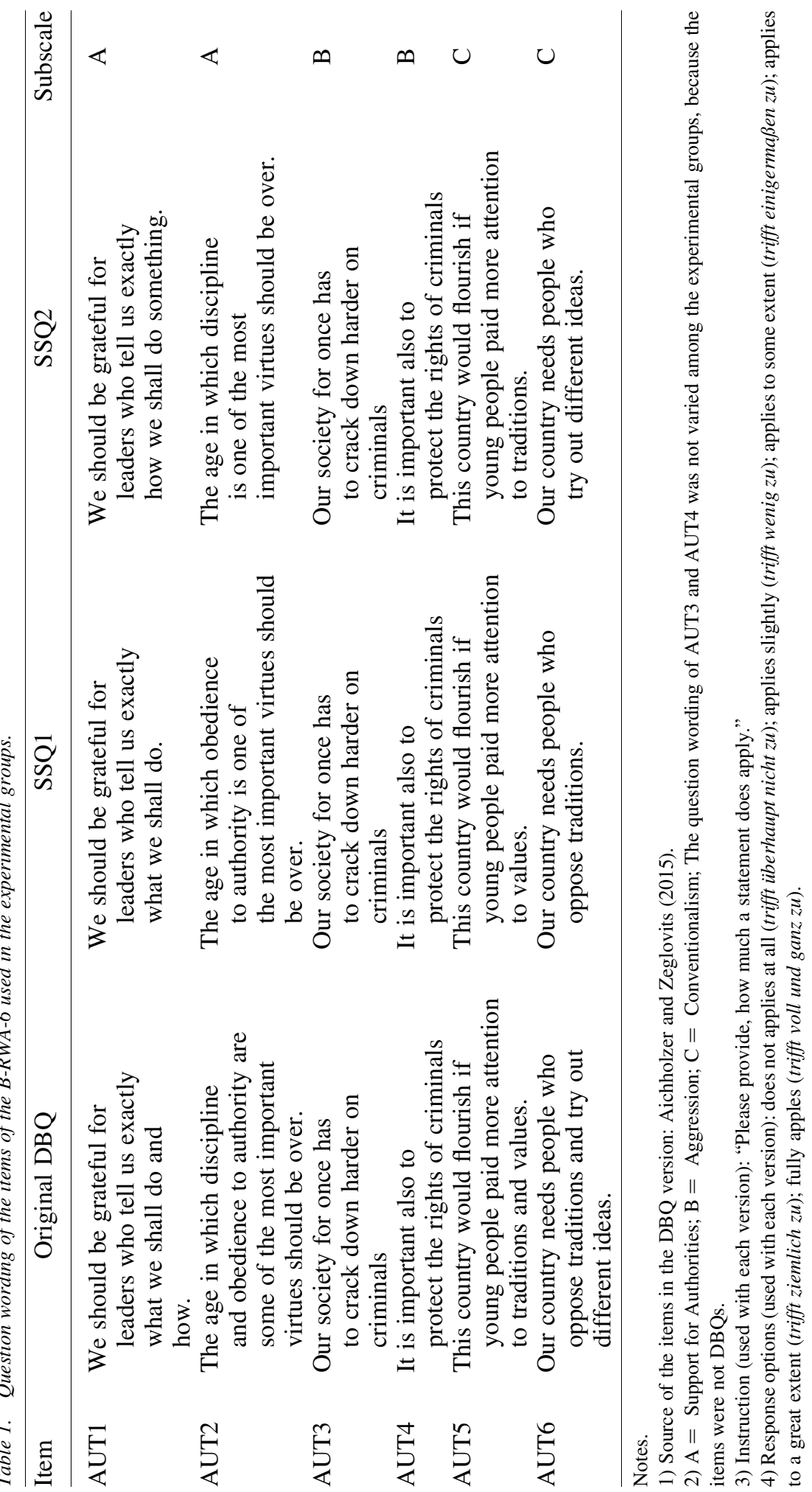


The inventories with DBQs like the B-RWA-6 are more typical in questionnaires, as multi-item sets usually consist of single sentences with or without subordinate clauses, where the double stimuli are two or more subjects, verbs, objects or their attributes. The PVQ inventory (Schwartz 2003) has a different structurebecause two separate grammatically independent sentences describe the subject that respondents have to evaluate with respect to the similarity to themselves. Some of the separate sentences are simple, while some contain dependent clauses or even double-barreled objects (e.g., item Trad1). Although this two-sentence structure of the PVQ is a less typical form of DBQ, it is worth comparing it with more typical DBQ structures, such as in B-RWA-6. The potential cognitive burden of DBQs might not only be due to their grammatical complexity, but more particularly to the task of evaluating two fewer or more different aspects as a single entity. Respondents have to conduct this task in the case of both inventories; therefore, the results obtained from them would be similar, although the inventories have a different structure. In addition, PVQ was included, because it is a relevant inventory used in large-scale population surveys, such as the ESS or GESIS Panel.

The author used four items of the PVQ (Schwartz 2003) from the questionnaire of the German ESS (2014). The PVQ measures ten basic values, grouped into four second-order values. The items used in this experiment assess the basic values "Tradition" and "Conformity", which belong to the second-order value "Conservation." "Tradition" and "Conformity" are strongly related to each other (latent correlation of .98, reported by Schwartz 2003). Tradition describes respect for and acceptance of traditional cultural or religious customs. Conformity is defined as a restraint of actions, inclinations, and impulses likely to upset or harm others who violate social expectations or norms (Schwartz 2003). The instruction and response alternatives - presented in Table 2 - were those of the ESS (2014) questionnaire. The original items are included in the column "original DBQ" in Table 2. The first and the second sentences of the original items of the PVQ differ in form, as the first sentence is shorter and contains a statement about importance of a value or a general kind of thinking about a value, whereas the second statement is somewhat longer and describes a tendency to a more concrete behavior or opinion. The first revised version therefore contained the first sentence (SSQ1 group), while the other revised version contained the second sentence (SSQ2 group) of the original PVQ items. Because of the differences in the length and structure of the sentences, the author decided to consistently incorporate the first sentence in one form and the second sentence in the other form and not to mix them in the forms. Otherwise, respondents could be confused when reading differently realized sentences in one form that might negatively affect measurement quality.

\subsection{Participants}

The data was collected in December 2016 using a commercial online access panel with a proportional quota sample approximately reassembling the German adult population aged 18 years or older. The participants used only a PC to avoid the side effect of other devices. Device was controlled at the beginning of the session; use other devices than PC lead to the exclusion from the sample.

Of the participants in the first experiment with the B-RWA-6 inventory $(\mathrm{N}=497)$, $50.3 \%$ were men. With respect to education, $29.6 \%$ had completed senior high school and 


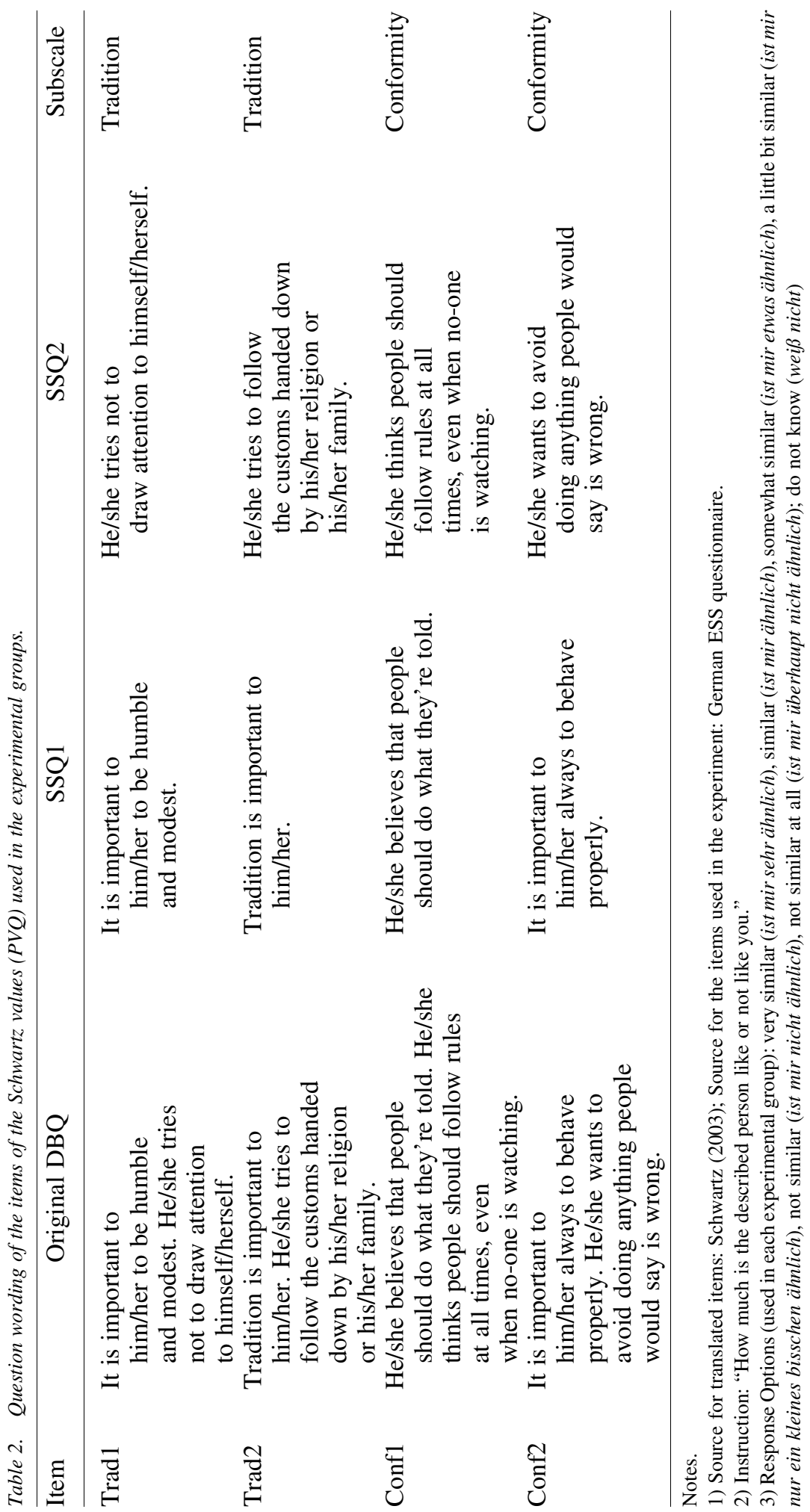


$30.8 \%$ secondary school. Concerning the age, $20 \%$ were younger than $40,34.6 \%$ were between 40 and 60 and $35.4 \%$ were 60 and older.

Of the participants in the second experiment with the PVQ inventory $(\mathrm{N}=435), 47.8 \%$ were men; $29.4 \%$ had completed senior high school and $30.6 \%$ had completed secondary school; $26.2 \%$ were younger than 40, 38\% were between 40 and 60, and $35.9 \%$ were 60 and older.

In both experiments, none of the experimental groups differed significantly $(p>.10)$ with regard to these respondent variables; the pertinent hypothesis was tested with a $\chi^{2}$ test.

\subsection{Data Analysis}

To address hypotheses $\mathrm{H} 1$ and $\mathrm{H} 2$ mean differences among versions were compared by means of Multivariate Analysis of Covariance (MANCOVA) and Univariate Analysis of Covariance (ANCOVA) with the SPSS 23 software. To control for the possible effects of respondents' gender, education, and age, the author included these variables in the analysis as auxiliary variables (covariates). To compare structures of inventories with respect to the latent variable measurement, the author made use of the framework of LVM (Muthén 2002) and implemented Multi Group Confirmatory Factor Analysis (MGCFA) with the Mplus 8.2 software. The author thereby examined measurement invariance between different experimental groups. This allows for an evaluation of the parallelisms of the versions with respect to their relevance to the latent dimension and comparability of measurements. The author first tested the exact measurement invariance (Meredith 1993) by evaluating configural, metric and scalar invariance. Configural invariance means that the same latent structure explains the observed means, variation, and covariation among the items in each of the groups, but does not allow for any comparisons between groups (Meredith 1993). Metric invariance means that an indicator has comparable strength of linear relationship with the latent variable and thus is equally relevant to it in each version (equality of factor loadings). Establishing metric invariance allows for comparison of correlations between latent variables or summarized scores (Hox et al. 2015; Meredith 1993) among the respective groups. Scalar invariance implies that the means of each of the observed variables are comparable associated with the latent means and therefore tap similar parts of latent continuum (equality of intercepts). Scalar invariance allows for a comparison of latent means or summarized scores (Hox et al. 2015; Meredith 1993).

The model fit of MGCFAs was evaluated using the chi-square $\left(\chi^{2}\right)$ test, the Root-MeanSquare Error of Approximation (RMSEA), and the Comparative Fit Index (CFI) (Beauducel and Wittmann 2005). The CFI should be 0.95 or higher, while an RMSEA of 0.08 or less indicates an acceptable fit (Hu and Bentler 1999). Robust Maximum Likelihood estimator (MLR) was used due to the non-normality of data in each experiment (Muthén and Muthén 2017). Concerning the exact measurement invariance, a significant change of $\chi^{2}$ (Meredith 1993) or a change of $\Delta \mathrm{CFI} \geq .01$ and $\Delta$ RMSEA $\geq .015$ indicate significant differences (Chen 2007).

In the structural equation modeling literature (Muthén and Asparouhov 2014), there is some criticism that the exact test of measurement invariance is too conservative and that 
metric and scalar invariance are consequently difficult to reach. The author therefore also implemented a more liberal alignment method (Muthén and Asparouhov 2014) using Mplus 8.2 software.

Reliability and validity were evaluated to assess measurement quality and to address the hypothesis H3. While reliability describes how far the variation in the data is due to the true variation and whether the non-systematic measurement error is negligible (Lord and Novick 1968; Raykov and Marcoulides 2011), validity refers to the empirical evidence that an inventory allows making conclusions with respect to the concept under investigation (Kane 2013; Messick 1989).

For the B-RWA-6, Aichholzer and Zeglovits (2015) report the composite reliability ranging between .60 and .65 that is a low, just acceptable size. For the PVQ subscales, Schwartz et al. (2015) report Cronbach's Alpha of a very low size (Alpha $=.33$ for Tradition and Alpha $=.53$ for Conformity) they found in the ESS 2012 data in Germany. Therefore, there would be a potential to increase measurement quality through an elimination of DBQs in both inventories.

The author used Composite Reliability as a method to assess reliability of different versions. This method is based on the "congeneric measurement model" and does not assume equality of factor loadings or error term covariances associated with the observed measures. The Composite Reliability coefficient $\left(\hat{\rho}_{x}\right)$ is estimated within the framework of LVM as follows (Raykov and Marcoulides 2011, 161):

$$
\hat{\rho}_{x}=\frac{\left(\hat{b}_{1}+\cdots+\hat{b}_{p}\right)^{2}}{\left(\hat{b}_{1}+\cdots+\hat{b}_{p}\right)^{2}+\hat{\theta}_{1}+\cdots+\hat{\theta}_{p}},
$$

where $b_{1}, \ldots, b_{p}$ are the factor loadings and $\theta_{1}, \ldots, \theta_{p}$ the error variances, obtained from the MGCFA (see Menold and Raykov 2015).

To assess validity coefficients, the author evaluated convergent (nomological) validity, as well as criterion validity. The convergent validity is evidenced through high correlations between different measures of the same or very closely related concepts (e.g., Lord and Novick 1968). Respondents therefore also administered the Short Scale of Authoritarianism (KSA-3) by Beierlein et al. (2014) as a to the B-RWA-6 alternative inventory on authoritarianism to provide data for the analysis of validity. KSA-3 consists of two subscales "Convention" and "Aggression" (with three items each). In order to evaluate validity, the size of expected correlations on the basis of theoretical considerations and/or results of past research must also be stipulated (e.g., Lord and Novick 1968). KSA-3 and B-RWA-6 represent alternative measurement instruments for the same latent concept (authoritarianism). Therefore, one can expect correlations with high effect sizes (larger than .50, Cohen 1992) between them. Expected correlations are shown in Table 7 in the results section, along with the results with respect to the validity coefficients in different questions wording versions.

The author also evaluated convergent validity for "Conformity" and "Tradition" of the PVQ. For this purpose, respondents administered the subscale "Security" of the PVQ (Schwartz 2003). "Security" can serve as measure of a similar concept, because it is the third sub-dimension of the second-order "Conservation" value, while "Tradition" and "Conformity" are the first two. The latent correlation between "Security" and "Tradition" 
vs. "Conformity" amounts to .78 in Germany in the ESS 2012 data (reported by Schwartz et al. 2015), so this size of correlation was also expected for the present study (Table 7).

Criterion validity is evidenced through replications of empirically proven relationships between a measure and a third variable (Raykov and Marcoulides 2011). The measures on "Security" of the PVQ can therefore serve as criterion for the B-RWA-6, since Beierlein et al. (2014) found the authoritarianism measured by the KSA-3 to correlate by .65 with "Security". Similarly, the KSA-3 inventory can be a measure of criterion for the PVQ values "Tradition" and "Conformity". Beierlein et al. (2014) reported correlations of the KSA-3 with Schwartz's "Tradition" $(r=.49)$ and "Conformity" $(r=.58)$, so that comparable sizes of correlation were expected to support validity assumptions in the present study (Table 7).

The author compared latent convergent or criterion validity coefficients among different question-wording groups using MGCFAs and Mplus 8.2 software. A similar procedure is described in detail in Raykov et al. (2018). The latent covariance between the related concepts thereby was divided by the square root of the product of the error variances of the two latent variables.

\section{Results}

\subsection{Parallelism of the Stimuli in DBQs}

\subsubsection{Mean Differences}

The first hypothesis assumes that the stimuli included in a DBQ are different in meaning and therefore not parallel. In such a case, if the DBQ version and its stimuli are randomly distributed among groups, and respondents separately evaluate each, there should be a notable mean difference among these groups. Concerning the items of the B-RWA-6, the ANCOVAs, which were conducted within a MANCOVA, revealed no significant mean differences between the three experimental groups for the first item (AUT1): "We should be grateful for leaders who tell us exactly what we shall do and how" (Table 3). Hence, the stimuli "what we shall do" and "how we shall do" included in the item AUT1 seem to have similar meaning (within the given sentence or context). As to expectations, there were no mean differences among the groups for the items AUT3 and AUT4 either. These items were not DBQs and those presentations did not differ among groups. However, such a result did not emerge for the remaining three items with experimental variation in question wording (AUT2, AUT5, AUT6). Table 3 shows that the means of these items differed significantly among the versions. The pairwise comparisons showed for the item AUT2 that only the SSQ1 group (with the stimulus "obedience to authority" as an important virtue) differed from the DBQ and the SSQ2 groups. The means in the latter two groups did not significantly differ from each other. The SSQ2 group included the term "discipline" as an important virtue, which was also the firstly presented stimulus in the DBQ group. Due to significant mean difference between the SSQ1 and SSQ2 groups, respondents differently evaluate the meaning of "discipline" and "obedience to authority", a result that supports the expectations of the hypothesis $\mathrm{H} 1$. 


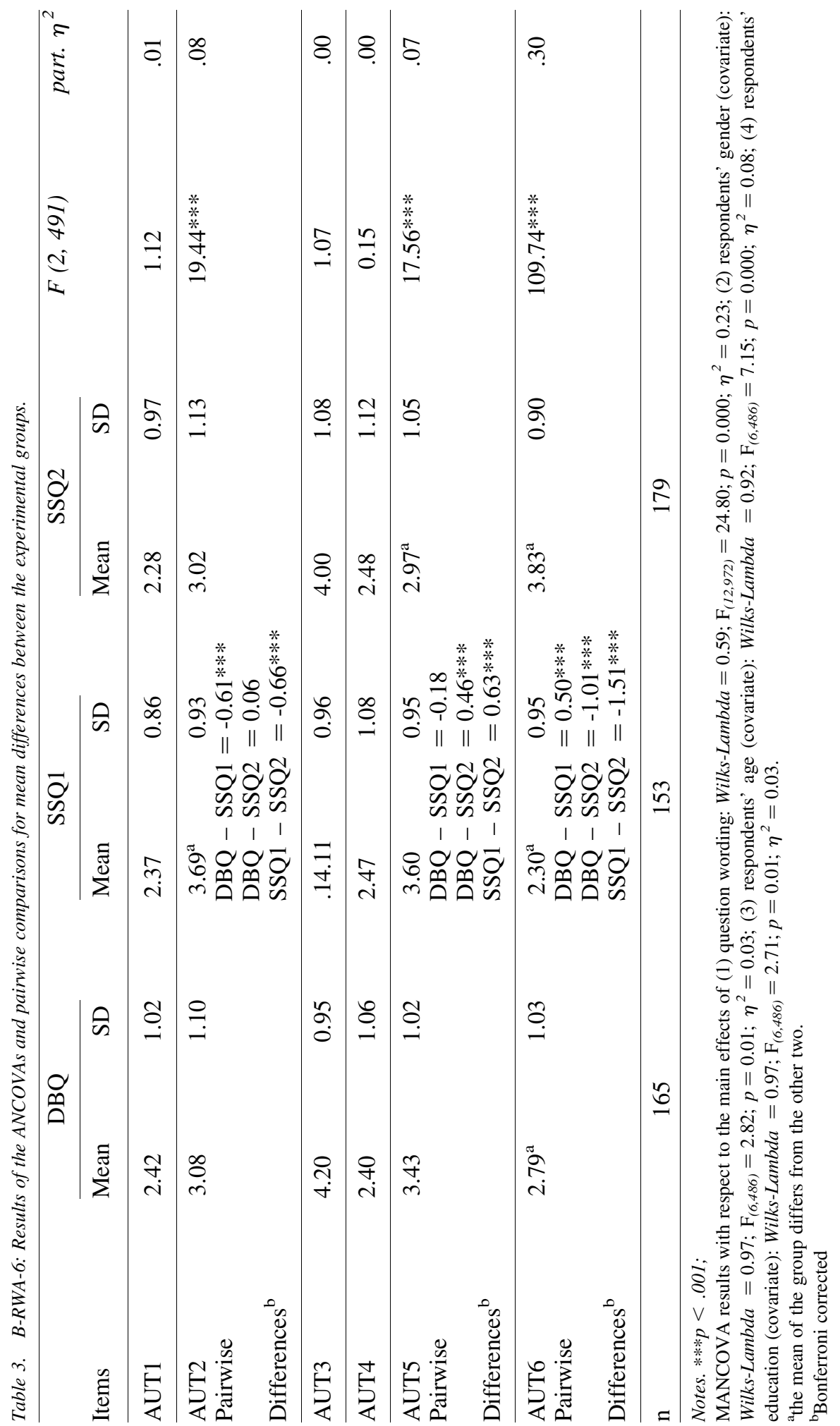


The pairwise differences for the item AUT5 also showed a significant mean difference between the SSQ2 group and other two groups, whereas there was no significant mean difference between the SSQ1 group and the DBQ group. The SSQ1 group contained the term "values" as an important issue for consideration by young generations, which is the second stimulus included in the DBQ. This means again that the DBQ and the SSQ1 versions are parallel in the meaning, but there is no parallelism for these both to the SSQ2 version. It also seems that, in contrast to the item AUT2, respondents in the DBQ of the AUT5 item considered the second stimulus presented, "values", when responding to it and disregarded the first stimulus presented. For the AUT6, however, one can see that the three groups were not parallel in meaning, because there were significant mean differences among them. Thus, respondents seemed to consider both stimuli when responding to the DBQ in AUT6, which explains its different meaning, as compared with the both single stimuli. Like the item AUT2, the results for AUT5 and AUT6 therefore supported H1 as well.

Table 4 provides an overview of mean differences for each item among the three experimental groups for the Schwartz's PVQ inventory. The means differed significantly among the groups for three out of four items (Trad1, Trad2, Conf2), in line with the expectation of the hypothesis H1. For both of the "Tradition" items, pairwise comparisons (Table 2) showed that respondents evaluated both parts of the DBQs differently. For these items, respondents also tended to focus on one of the stimuli, and not on both, since there were significant mean differences between the DBQ and only one of the single stimulus groups. For the first item (Trad1), there was no significant mean difference between the DBQ group and the SSQ1 group, which evaluated the first sentence of the DBQ ("important to be humble and modest"). By contrast, the mean of the DBQ, as well as that of the SSQ1 group, was significantly different from the mean of the SSQ2 group with the second sentence of the original DBQ item ("tries not to draw attention to himself/herself"). For the Trad2 item, the SSQ1 that contained the first sentence of the initial DBQ ("tradition is important to her/him") differed from it, while there was no difference in means between the DBQ and the SSQ2 that contained the second statement ("tries to follow the customs"). Here, similar to the item AUT5, in the case of DBQ, respondents seemed to respond to the second stimulus presented and not to the first stimulus. In the case of Conf2 item, like in the case of Trad2, the parts of the DBQ were differently evaluated, and the DBQ differed in meaning from the version containing the first sentence (SSQ1), but not from the version that contained the second sentence (SSQ2).

In sum, the majority of the results supported the assumption in hypothesis $\mathrm{H} 1$ that stimuli in a DBQ differ in meaning. The results show that respondents tended to evaluate the stimuli included in a DBQ differently. Respondents also seemed to pursue two different strategies in handling the stimuli in a DBQ: (1) evaluating one of the stimuli or (2) considering both of them. The respondents seemed to apply the first strategy more often, which was the case in two of the four DBQs in the B-RWA-6 inventory and three of the four items in the Schwartz's sub-scales. If respondents applied the strategy to evaluate only one of the stimuli, they did not behave in a systematic manner as they sometimes considered the first stimulus of the DBQ and sometimes only the second one. 


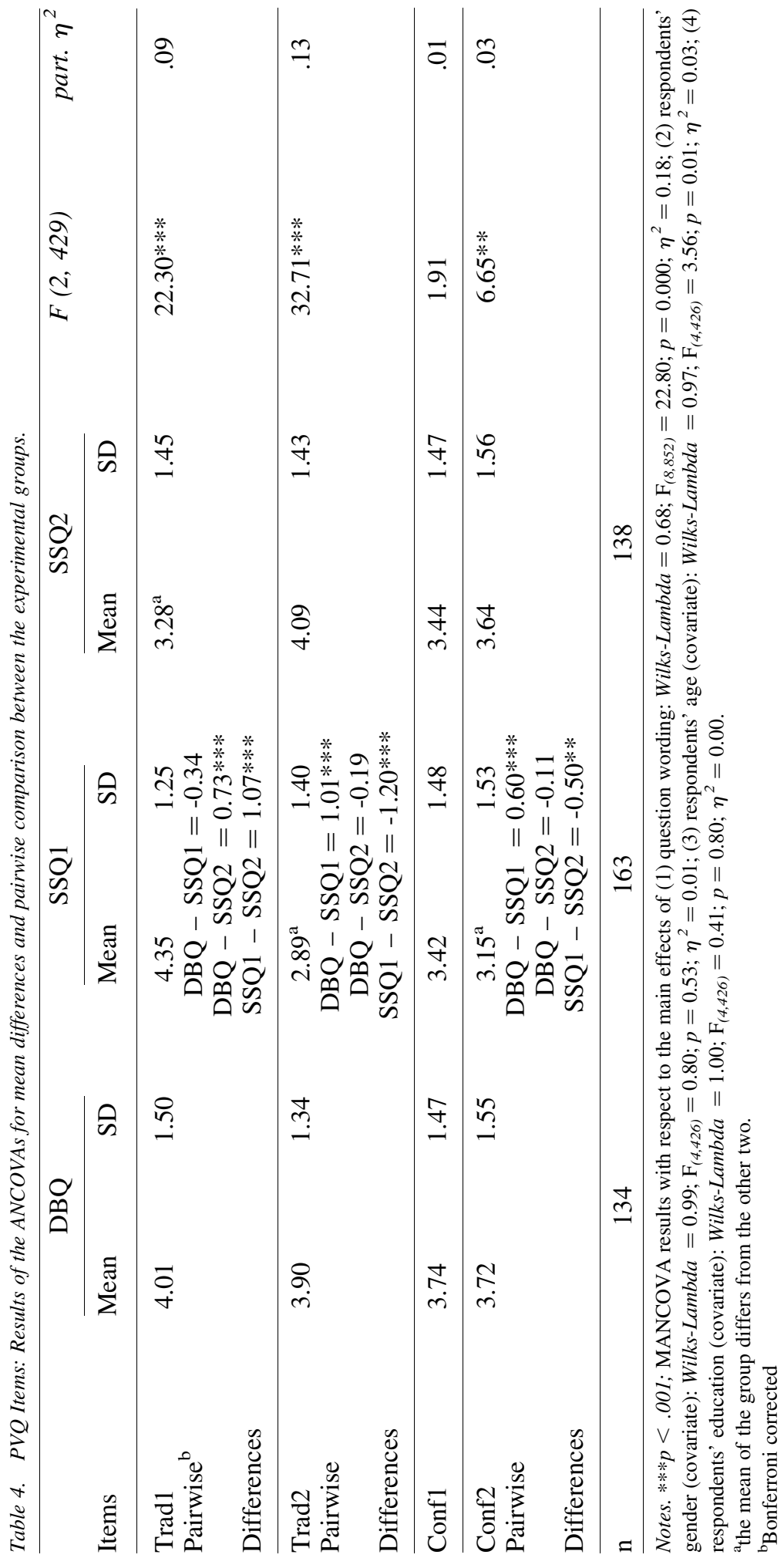




\subsubsection{Measurement Invariance}

In this section, the author evaluates the assumption of the parallelism of the latent structures of different question wording versions by means of measurement invariance analysis. In the first step, the measurement model without any restrictions on equivalence of model parameters (a baseline congeneric model, e.g., Raykov and Marcoulides 2011) was specified. For the B-RWA-6 Aichholzer and Zeglovits (2015) postulated a general factor for authoritarianism behind the three sub-factors, consisting of two items each (Figure 1). Because of the reversed formulation of the items for each sub-factor, Aichholzer and Zeglovits (2015) also modeled a latent "method" variable that claimed for potential acquiescence bias (the "bi-factor model", Reise 2012). The author was not able to use the general factor model with a method effect (Figure 1), because of serious specification problems in the present data (convergence problems). Since the three subfactors are supposed to represent a latent dimension, one factor can also explain the common variation of the six items. The single-factor MGCFA with a latent method effect was identified, but there were still specification problems (negative error variance of the item AUT1, and three to four of the six items had not-significant factor loadings in all groups). The model fit was non-satisfactory as well $\left(\chi_{(\mathrm{df}=26)}^{2}=46.76, p<.001 ; R M S E A\right.$ $=0.07 ; C F I=0.87$ ). The next step, after inspecting modification indexes, was to respecify the method factor. The author allowed only the items with the positive association with the latent variable to load on the method effect as shown in Figure 2. The method effect was assumed to be similar in each group. For the third group, however, a different method effect was specified for the item AUT2 to correct for the corresponding misspecification. Next, in the DBQ group, a correlated error term between the items AUT1 and AUT2 was implemented. This model yielded an acceptable model fit $\left(\chi_{\text {(df }}^{2}\right.$ $=26)=37.39, p>.05 ;$ RMSEA $=0.05 ; C F I=0.93)$. This model also resolved the former problem of negative error variances and non-significant item loadings. The item

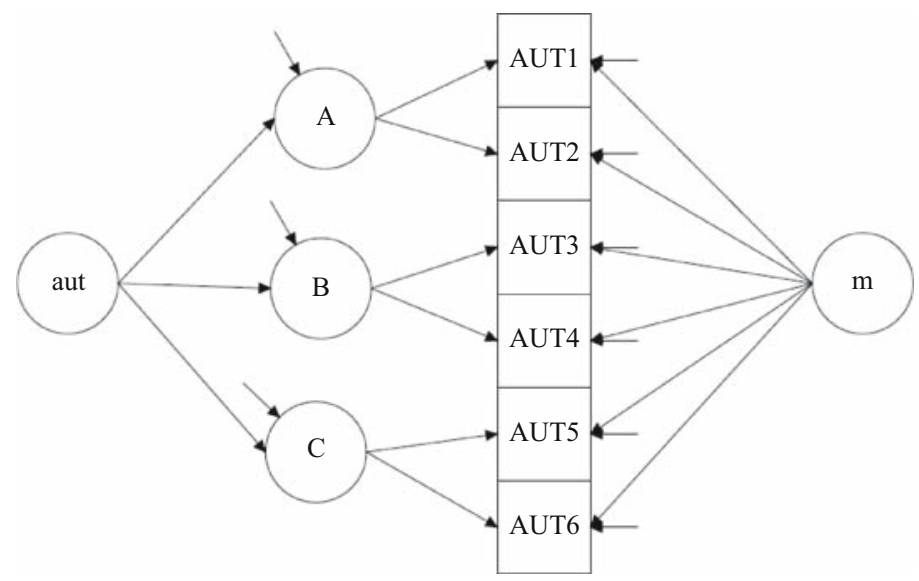

Fig. 1. B-RWA-6 General factor model for the B-RWA-6 with method effect, after Aichholzer and Zeglovits (2015).

Notes. aut: general factor authoritarianism; $m$ : method effect; loadings on $m=1:$ AUT1, AUT3, AUT5; loadings on $m=-1$ : AUT2, AUT4, AUT6. A = Support for Authorities; $B=$ Aggression; $C=$ Conventionalism; AUT1 TO AUT6 = indicators, see Table 1. 


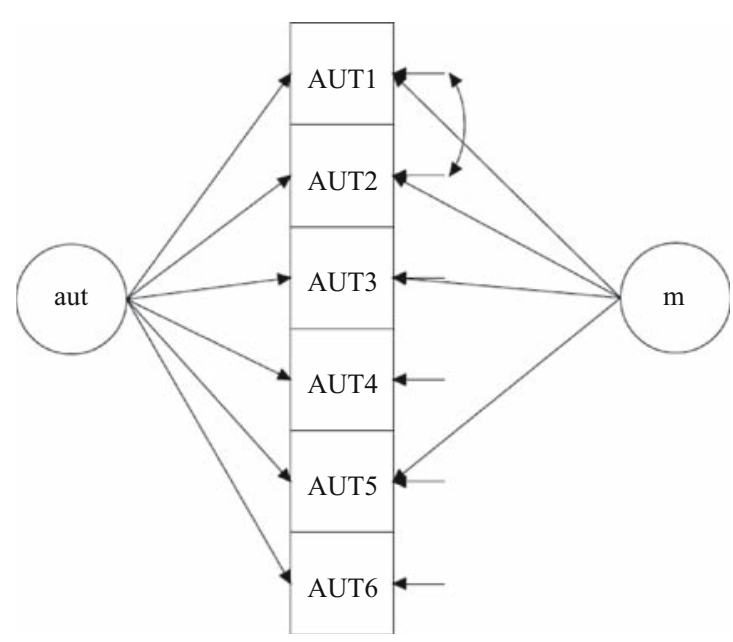

Fig. 2. One-factor model with modified method-effect for the B-RWA-6.

Notes. aut: factor authoritarianism; m: method effect; AUT1 TO AUT6 = indicators, see Table 1. Loadings on $m=1:$ AUT1, AUT3, AUT5; loading on $m=0: A U T 2$

AUT6 in the SSQ2 group only did not exhibit a significant factor loading. The described configural model served as a baseline model for the evaluation of measurement invariance, reliability and validity.

The results of the exact measurement invariance test for the B-RWA- 6 are provided in Table 5. Restricting the factor loadings being equal, significantly decreased the model fit as accounted by the difference in $\chi^{2}, R M S E A$ and $C F I$. There was therefore no exact metric invariance between the groups. Restricting intercepts to being equal further significantly (and dramatically) decreased model fit, meaning that there were notable differences in intercepts between the experimental groups.

The alignment analysis revealed that the factor loading of the AUT2 in the SSQ1 group significantly differed from those in other groups (see Appendix, Section 5). The difference of intercepts between this group and the other two groups are also obtained for AUT2 and AUT5 items. In addition, the intercepts of the item AUT6 differed between the three

Table 5. Results for testing of the exact measurement invariance in two experiments by question wording groups.

\begin{tabular}{llccccc}
\hline Model & \multicolumn{1}{c}{$\chi^{2}(d f)$} & \multicolumn{1}{c}{$\Delta \chi^{2}(d f)$} & RMSEA & $\Delta R M S E A$ & $C F I$ & $\Delta C F I$ \\
\hline \multicolumn{7}{c}{ B-RWA-6 } \\
configural & $32.39(26)$ & - & .051 & - & 0.928 & - \\
metric & $82.37 * * *(38)$ & $44.98 * * *(14)$ & .084 & .033 & 0.718 & .210 \\
scalar & $281.39 * * *(45)$ & $208.04 * * *(8)$ & .180 & .096 & 0.000 & .718 \\
\hline \multicolumn{7}{c}{ PVQ } \\
configural & $1.39(3)$ & - & 0.000 & - & 1.000 & - \\
metric & $24.91 * * *(11)$ & $24.61 * * *(8)$ & 0.093 & .093 & 0.934 & .066 \\
scalar & $182.21 * *(19)$ & $171.96 * * *(8)$ & 0.240 & .147 & 0.223 & .711 \\
\hline
\end{tabular}

Notes. $\Delta \chi^{2}$ : with scaling correction factor for MLR; $* * * p<.001$ 
groups (see Appendix). These results therefore reassembled the results with respect to the differences of means of single items presented in the above section.

To conclude, the latent measurement structure of the B-RWA-6 was different between the two single stimulus groups concerning the loadings and intercepts, a robust result obtained by different methods of testing measurement invariance. The results therefore supported the hypothesis $\mathrm{H} 1$ and show that respondents evaluated the stimuli of the DBQs differently so that these stimuli cannot be assumed to be parallel in meaning. The aligment method showed that there were differences between the DBQ version and one SSQ version, while the structures were similar between the DBQ and the other version with SSQs.

For the "Conformity" and "Tradition" of the PVQ, the configural two-factor model (Schwartz 2003) was associated with a perfect goodness-of-fit $\left(\chi_{(\mathrm{df}=3)}^{2}=1.39, p=0.71\right.$, $R M S E A=.00, C F I=1.00)$. The item loadings ranged from .37 to .89 . Therefore, the configural invariance can be assumed among the groups (Table 5). Modeling the equality of factor loadings significantly decreased the goodness of fit, according to the change in $\chi^{2}, R M S E A$ and $C F I$. Restricting the intercepts to being equal noticeably decreased the model fit even further. The exact metric and scalar invariance were therefore not observed between the DBQ and its single stimulus versions. The results of the test of measurement invariance with the alignment method are shown in Appendix. The SSQ1 group had significantly smaller latent means for both latent factors than the DBQ group. The latent mean for Tradition in the SSQ1 group was also lower than in the SSQ2 group. Factor loadings and intercepts for both two items of "Tradition" differed among the experimental groups; a to the comparison of single items comparable result.

The results for both concepts were therefore comparable, regardless of which measurement invariance test was used, and supported the assumption of the hypothesis H1 concerning the difference of meaning between the stimuli of the DBQs.

\subsection{Response Times}

In each experiment, all the items of a version were presented on a screen and response times per screen in milliseconds were measured (absolute response times). Outliers and skewed response times were dealt with by transforming data as described by Yan and Tourangeau (2008). Firstly, data were recoded separately for each experiment, while observations beyond the upper and lower one percentile were replaced with the upper and lower one percentile values. Secondly, the recoded data were log transformed. Because the length of each text version was different, the author also compared response times in milliseconds per character to disentangle the cognitive effort associated with the response process and the different amounts of time needed to read each length of the text. To calculate response times per character in each experimental group, the recoded response times were divided by the number of characters and then $\log$ transformed. Table 6 shows the means and standard deviations for logarithmically transformed data by experimental group, as times per screen and times per character.

For the B-RWA-6, a significant difference in response times per character only existed between the two single stimulus groups (see Table 6, pairwise comparisons), where respondents spent more time processing a character of the SSQ1 version. The DBQ group 


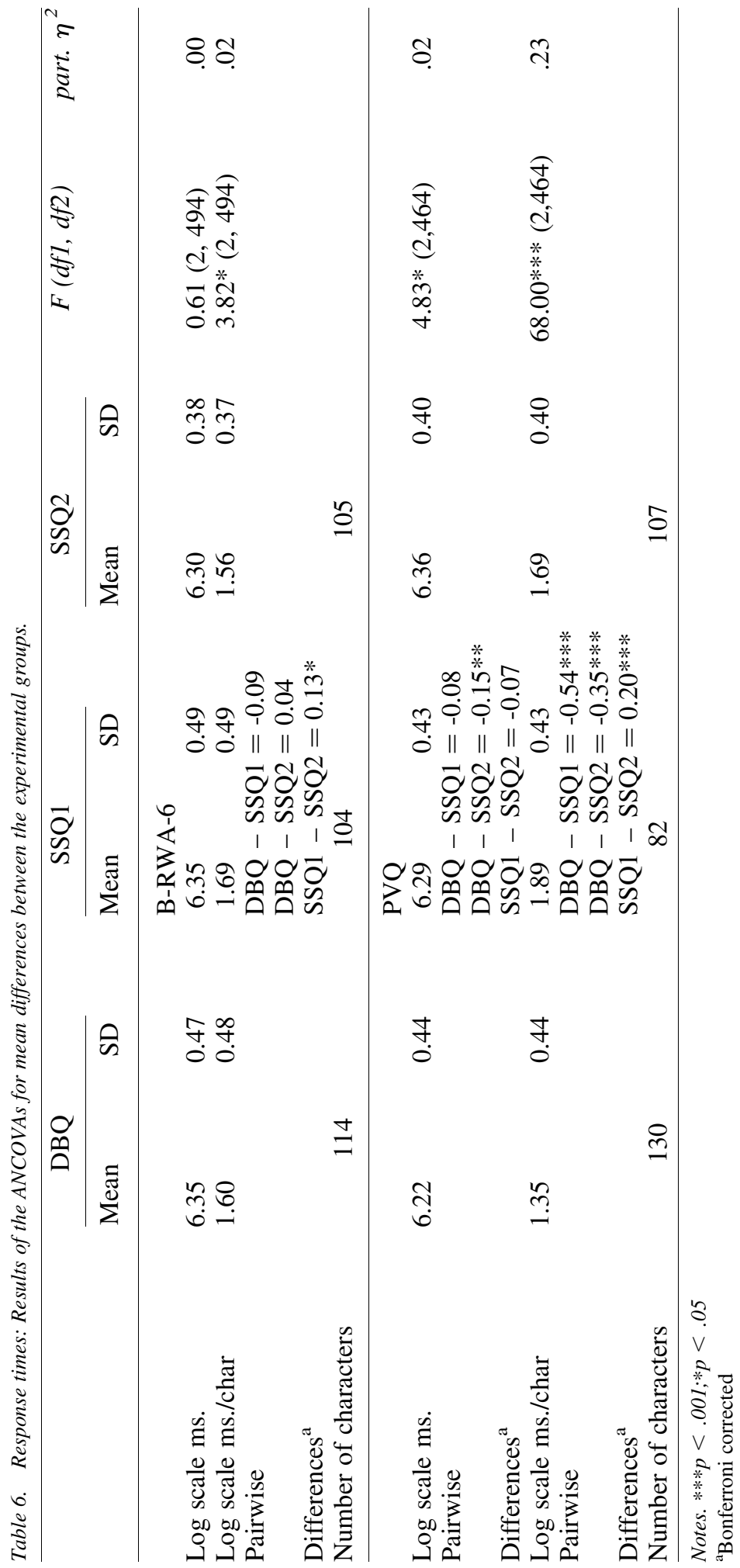


did not differ from the single stimulus groups. For the Schwartz's subscales, there was considerably more text to read in the case of DBQs; the least amount of reading text was in the SSQ1 version. Surprisingly, there was no difference in response times between the DBQ and SSQ1 versions. Response times were significantly lower in the DBQ than in the SSQ2 version. In addition, respondents spent significantly less time per character on the texts in the DBQ than in the other two groups. Respondents spent most time per character in the SSQ1 group, as compared with the other groups (Table 6).

Since respondents did not spend more time on DBQs than on the versions with single stimuli or they even needed less time to respond to DBQs than to their shorter single stimulus versions, there was no empirical support for hypothesis $\mathrm{H} 2$ that expected higher response latencies for DBQs. The results with respect to response times therefore support the interpretation of the findings presented in the above section that respondents tended to disregard a part of the question in the case of DBQs and exhibited satisficing behavior.

\subsection{Reliability}

Reliability was calculated on the basis of the configural models for both inventories (Table 5). In the first experiment, the reliability of the six items of the B-RWA-6 adhering to a single latent dimension was estimated. The correlated error term in the DBQ group was attained to the error variance (Raykov 2012). The composite reliability was estimated at $\rho=.61$ (SE $=.05 ; 95 \%$ C.I. [.51-.71]) in the DBQ group, which is a low reliability. The reliability was also low in the SSQ1 $(\rho=.61$; SE $=.04 ; 95 \%$ C.I. [.53-.70]) and SSQ2 group $(\rho=.54 ; \mathrm{SE}=.07 ; 95 \%$ C.I. [.41-.68]) and there were no significant differences in the size of reliability coefficients between the three versions of the questionnaires.

For the PVQ items, the composite reliability for general structure (Raykov 2012) was again low for all experimental groups. It was somewhat higher for the DBQ questions $(\rho=.65 ; \mathrm{SE}=.05 ; 95 \%$ C.I. [.56-.74]) than for the questions with the first sentence (SSQ1: $\rho=.60 ; \mathrm{SE}=.05 ; 95 \%$ C.I. [.50-.70]) and did not differ appreciably between DBQ questions and questions with the second statement (SSQ2: $\rho=.68$; SE $=.04 ; 95 \%$ C.I. [.60-.77]). The differences between the groups were again not significant.

In sum, the differences concerning reliability were not significant, so that - when considering reliability - hypothesis $\mathrm{H} 3$ that expected increased reliabilities in single stimulus questions has to be rejected.

\subsection{Validity}

Table 7 provides an overview of differences in validity coefficients among the experimental groups. We look at the correlations between the B-RWA-6 and the KSA-3 (convergent validity for the B-RWA-6) in experiment 1 . For the "Conservation" of the KSA-3, there was a correlation with the B-RWA-6 of expected high value (.50 or higher) in the DBQ and SSQ2 group. For the "Aggression" of the KSA-3, the expected high value (.50 or higher) was again reached in the SSQ2 group but not in the SSQ1 and DBQ groups. However, for both KSA-3 scales there were only significant differences in validity coefficients between the two single stimulus groups. In addition, in the SSQ1 group there was no significant relationship between the B-RWA-6 and "Aggression" of the KSA-3, which means that two alternative measures of the same concept did not significantly inter-correlate. 
Table 7. Validity coefficients, expected, by question wording group and their pairwise differences.

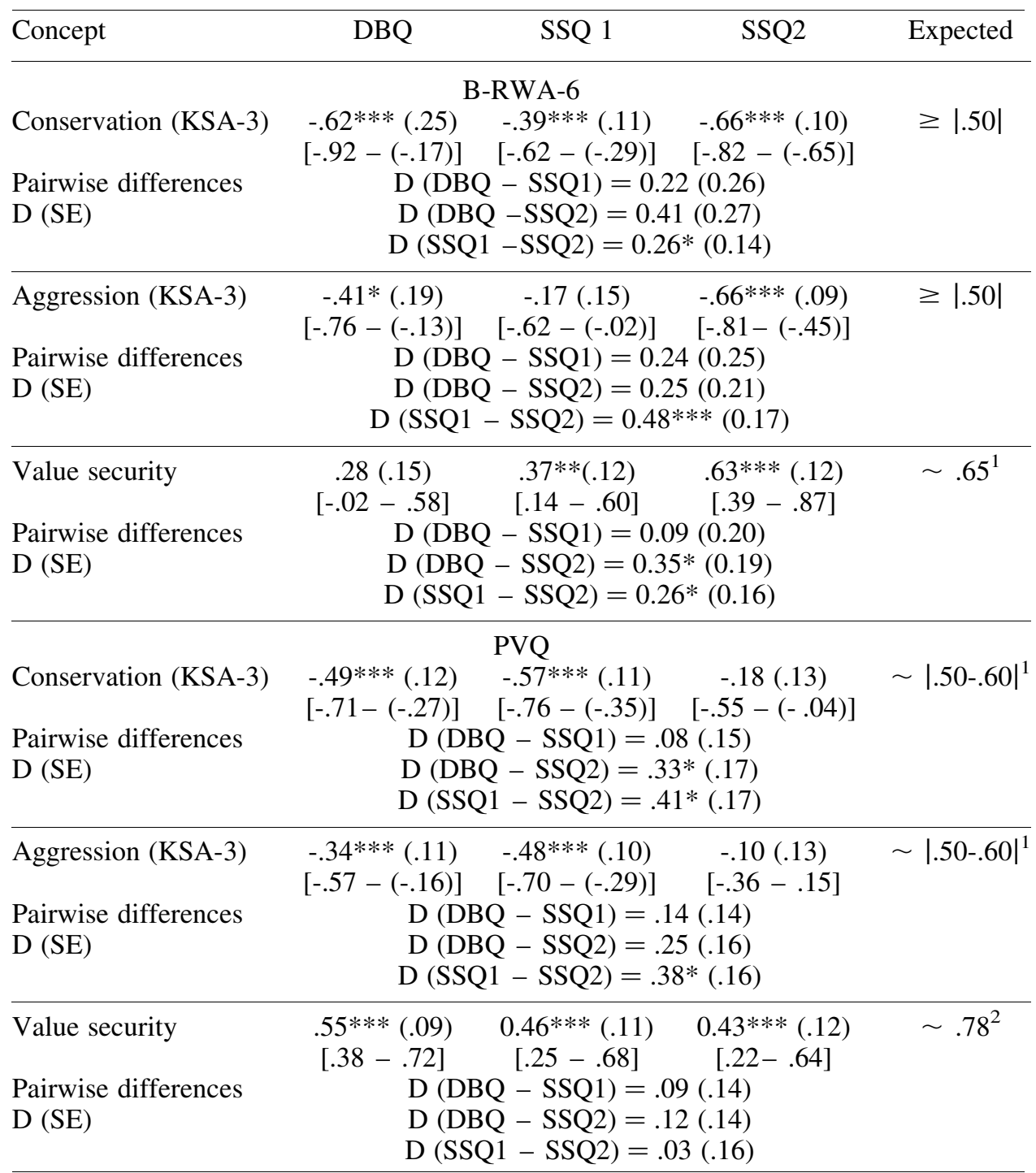

Note. $* p<.05 ; * * p<.01 ; * * * p<.001$; ${ }^{1}$ Source: Beierlein et al. $2014 ;{ }^{2}$ Source: Schwartz et al. 2015.

For the criterion validity of the B-RWA-6, evaluated through the latent correlation with the Schwartz's value "Security", the lowest and non-significant correlation was in the DBQ group and it was higher in both single stimulus groups. The expected size of correlation was only reached in the SSQ2 group, where it was also significantly higher than in the DBQ $(\mathrm{D}=.35, \mathrm{p}<.05)$ and the SSQ1 group $(\mathrm{D}=.26, \mathrm{p}<.05)$.

In the case of the PVQ, the latent correlations of "Conformity" and "Tradition" with the subscale "Conservation" of the KSA-3 were somewhat higher in the SSQ1 group than in the DBQ group, but these correlations were within the expected range $(.50-.60)$. The result in the SSQ2 group was critical because a significant latent correlation with the 
"Conservation" as measured by KSA-3 was not obtained. The pattern for the latent correlations with the "Aggression," measured by the KSA-3, was similar: The correlation in the SSQ1 group was close to the benchmark, which was not the case in the DBQ group, while the correlation was very low and non-significant in the SSQ2 group. One remarkable result was again that there were strong and significant differences between the two single stimulus groups. Thereby, there was a strong validity loss for one of the parts of the former DBQs (the second sentences), while the validity scores tended to be higher than in the DBQs for the other parts (the first sentences). Inspection of the correlations with a related value (Security) showed higher values in the DBQ than in both single stimulus groups. However, none of the correlations met the benchmark and the differences among groups are neither highly pronounced, nor significant.

The findings of two experiments were therefore comparable. The convergent or criterion validity coefficients were either equal or higher in one of the single stimuli groups than in the DBQ group, but were lower in other single stimuli group. The results provided some support for hypothesis H3. Using SSQs instead of DBQs could increase validity, but this only applied to one of the SSQ versions. The evidence for validity was insufficient with the other SSQ version. This also showed that the respondents considered or evaluated the two stimuli in DBQs differently.

\section{Discussion and Conclusions}

One of the research aims of the present experimental study was to show that the double stimuli in standard social science inventories could be evaluated as having different meanings (stipulated in hypothesis H1). This assumption is found in many textbooks that discuss why DBQs would be problematic (Le Payne 1951; Oppenheim 1992). However, because there is a lack of empirical evidence on DBQs and because they are very common in inventories, the author considered that those who create inventories might not be aware of potential serious differences of stimuli and assume that they transport similar or comparable meaning and suit to each other. The results for both inventories under investigation mainly support the hypothesis $\mathrm{H} 1$ and show that stimuli included in a DBQ have a different meaning for the respondents. The author evaluated eight items (from two inventories) and for six of them significant mean differences were obtained, if the stimuli were individually responded to. This clearly supports the assumption the meaning of the stimuli may potentially differ in a majority of the material of the present study. Looking at the item sets as instruments to measure latent variables, lack of metric and scalar measurement invariance among the versions clearly supports the assumption of difference in the meaning of the stimuli. Absence of metric invariance means that the stimuli differ with regard to their relevance to the latent variable (strength of the linear relationship with the latent variable). Lack of scalar invariance means that stimuli are tapping different latent means and therefore differ not only in the strength of the relationship with the latent variable, but also in the meaning ascribed to it.

The author used two established and well-documented inventories on opinions with very differently structured double stimuli to evaluate the assumption of potential differences in meaning between the stimuli of DBQs. Despite these different structures, a common feature of the DBQs in both inventories was such that respondents had to evaluate 
two issues as part of a compound in one single question. If the results obtained from the two inventories were not comparable, the effect could not be explained by this commonality of the DBQs. Hence, the results for both inventories were strongly comparable and this strengthens the conclusions with respect to this common problem of DBQs.

Differences or similarities in stimuli in a DBQ (potential and particularly those from the point of view of respondents) is a key characteristic that may impact respondents' cognitive processes and data quality. If the stimuli have similar meaning, the consequences for the cognitive process would not be very severe for the respondents' cognitive burden, as they might disregard one of the stimuli without a negative impact on measurement quality or provide a compound response without difficulties. However, as in the present data the stimuli mainly differed in the meaning, the author was not able to observe the potential impact of stimuli that are similar in meaning. More research on this topic is needed to support the above assumption. Nevertheless, one might also ask why researchers require the redundancy and unnecessary complexity associated with a DBQ with similar stimuli. If the meaning of stimuli is (or has a potential to be) different, the consequences might be more severe for both, respondents' cognitive process and data quality.

The remaining results could only be interpreted in the light of the former finding that the stimuli in DBQs are of rather different meaning. What are respondents doing in such a case? Do they disregard one of the stimuli or try to integrate both to a response? A frequent observation (for both inventories under investigation) was that the mean of one item with one stimuli of a DBQ did not differ from it notably, but there was a strong difference between the DBQ and the other stimulus. The author concludes from this observation that in a DBQ respondents attend to one of the stimuli (namely to that for which - if included in a SSQ - there was no mean difference from the DBQ). A less frequent observation was that respondents also tried to integrate the stimuli, as the mean of a DBQ differed from the other two versions (and the latter from each other). The strategy which respondents use and the reasons why they focus on one or other stimulus appears to be item specific (or rather content specific) and dependent on the salience of one word in a respondents' memory, on the familiarity of the word, or on its relevance to the concept from the point of view of respondents. More research is needed to understand these processes.

The next finding was surprising, because there were no differences in the time respondents took to respond to the DBQs or analogous questions with single stimuli, although there was often more text to read in a DBQ than in the questions with single stimuli. The hypothesis H2, that expected higher response times for DBQs due to the respondents' burden, was not corroborated. Some respondents even spent less time to respond to DBQs than to SSQs. Again, the results with respect to the response latencies were generalizable over both inventories. These results do not support previous findings by Bassili and Scott (1996), who observed higher response latencies for DBQs in their telephone study with students. As the present study was a self-administered online survey, the differences in findings could be due to mode difference. Next, the participants of the study by Bassili and Scott (1996) were highly educated, while the sample of the present study also contained less educated respondents. This is in line with the satisficing approach that expects satisficing behavior to be higher if the task difficulty is higher and 
respondents' cognitive abilities are lower (Krosnick 1991). Therefore, the presented findings with respect to the response times are consistent with the assumption of cognitive shortcuts by respondents who had to work on a difficult task. The results with respect to response times demonstrate respondents' focus on one of the stimuli in a DBQ, but not on both. Apart from the satisficing explanation that is in line with the observation of strongly comparable means between the DBQ and one of the SSQ versions (but not with the other), there are also alternative explanations available, that is, a stimulus is easier to understand in the context of other stimulus. However, this explanation is not plausible in the light of the results obtained for the mean differences and measurement invariance: Why is the version with one stimulus comparable to DBQ but not the other version? If respondents evaluate the double stimuli (with different meanings) in the context of each other, all three versions should differ in means and latent variable structures (a result found for one item but not for other items).

The results of the present study therefore support textbook arguments that the different parts of compound DBQs have a different meaning and that respondents consider one of the parts and disregard the other (e.g., Bradburn et al. 2004; Le Payne 1951; Oppenheim 1992).

With respect to the negative impact of the DBQs on data quality, no significant effect on reliability is observed, so that initially low reliabilities did not increase when using SSQs. This means that stimuli in DBQs (although different in meaning) did not have a potential to increase reliability, neither together, nor separated. Therefore, results may differ, if more reliable instruments with DBQs were revised.

However, the use of a DBQ or one of its parts, in fact, affected validity scores. The results show that convergent validity can increase when respondents have to evaluate one stimulus in each question and not two in DBQs. However, a strong and unexpected result was a gap in validity scores between the two single stimuli versions. This result shows that (if the stimuli are different in meaning) keeping one stimulus of an instrument that used to be a DBQ would be associated with a serious validity loss, which resulted for both inventories. Removing irrelevant stimuli is a frequent suggestion for repairing a DBQ (Olson 2008). The present results show that stimuli differ in meaning, also with respect to the pertinent latent construct, and one might not be aware of this difference or of whatever stimulus is a more optimal or prominent measure of the latent variable. Therefore, deleting a stimulus from a DBQ without knowing what stimulus in the DBQ is construct relevant would be a risky operation. For example, one can revise the items on the Schwartz's values assuming that more specific items were easier to respond to (according to the corresponding suggestions in textbooks, e.g., Dillman et al. 2014). As a consequence, one might use an instrument containing only the second sentences of the original PVQ (like the SSQ2 group in the present data). This researcher would then be very surprised if he or she obtains no significant correlations to the relevant third variables. There is also a risk of arriving at non-significant results for tests of hypotheses. The results of this study imply that one should be cautious when deleting stimuli in a DBQ. If a DBQ has to be revised, both stimuli in the pertinent two single questions should be tested in split ballot experiments or presented subsequently and examined with respect to possible improvement of validity. Taking into account the effort and costs of such revisions, it would be better to avoid the DBQs in questionnaire design from the outset. 
An alternative possibility to revise a DBQ is to generate a single item for each of the stimuli and use them together in an inventory. While such a revision is easy to implement for PVQ (that means evaluation of each of the sentences as separate items), it is much more difficult to do so for other inventories such as B-RWA-6. Consider an inventory consisting of items: (1) "We should be grateful for leaders who tell us exactly what we shall do"; (2) "We should be grateful for leaders who tell us exactly how we shall do something."; (3) "The age in which obedience to authority is one of the most important virtues should be over"; (4) The age in which discipline is one of the most important virtues should be over". . . and so on. This means, having an item for each stimulus of a DBQ in one version requires significant rewording of the second sentence to avoid repeating contents in an item set. This calls for a strong change to the items what would have also introduced a higher error variance (in an experimental setting) and was the reason why the author of present article has not looked at the possibility of building a sentence for each stimulus in an inventory. Another disadvantage of such a revision for the B-RWA-6 (that is typical for inventories with DBQs in the social sciences and psychology) is that a twice as long questionnaire is needed, which also increases the complexity of respondents' work and is less economic. Hence, it is possible that for the PVQ a revision in which each sentence is presented as a separate item is sensible. Further research should address this question.

Several limitations of the presented study require attention. Owing to the fact that a commercial assess panel was used, the generalizability of the presented results to other settings is restricted. The present research addressed the DBQs, in which the stimuli were connected with "and" or with comparable grammatical constructions. The results therefore do not apply to other complex questions, such as presuppositions or use of "or". Two inventories were also involved, so that more research with other inventories and concepts, that is, behavioral questions, is needed. Although the two inventories differ in regards to the question form and complexity of DBQs, strongly comparable results emerged for both inventories. This allows similar results to be expected for other kinds of DBQs in which stimuli are enumerations or grammatically independent parts of a compound entity.

The results of the present study are in line with the assumption that respondents evaluate the double stimuli of a DBQ differently. The results also reflect that there would be a potential negative impact of DBQs on data quality as compared with one of the forms containing a single stimulus. Based on these results, the author shares the suggestion in the textbooks to avoid DBQs. In addition, the author suggests being cautious when revising existing DBQs. The author was surprised many times by the present results as the aim of the study was to empirically test a very old wisdom (a supposedly easy task). The straightforward expectations arising from this wisdom could only be supported with respect to the assumption that DBQs might include stimuli that are different in meaning. The expectation of a negative impact of DBQs and the positive one of the SSQs on response latencies and measurement quality was not as easy to show as initially expected. This seems to be because the stimuli in a DBQ would not only have a different meaning, but also different associations with the latent variable (as shown by the present research). The use of DBQs by respondents and their impact are less well understood and need more research, for example with respect to the negative impact of stimuli with similar meaning. 
Further research should also address similarities and differences between DBQs and questions with presuppositions (Kay and Fillmore 1999) to shed more light on the cognitive processes behind them and to provide a more solid basis for advice on questionnaire design. Next, stimuli connected with "or" should be addressed as well, as the author is not aware of any empirical studies of this structure.

However, it is also important to consider whether it would be better to spend time and money to better understand the practice of using DBQs or if it would just be better to avoid them in inventories? Of course, the avoidance is difficult if established inventories are used, as was also clearly shown by the present article. However, if these inventories have sufficient reliability and validity, one can reuse them due to the lack of alternatives. If one tries to revise inventories (i.e., to adapt them to the current issues) or develop new inventories, the authors' strong advice is to avoid DBQs.

\section{Appendix}

\subsection{Results for the Alignment Method}

\section{B-RWA-6}

Notation:

DBQ: 1, SSQ1: 2; and SSQ2: 3.

Non-equivalent parameters are presented in brackets.

Loadings

AUT1 123

AUT2 1 (2) 3

AUT3 123

AUT4 123

AUT5 123

AUT6 123

Intercepts/Thresholds

AUT1 123

AUT2 1 (2) 3

AUT3 1223

AUT4 123

AUT5 1 (2) 3

AUT6 (1) (2) (3)

Table A1. Factor mean comparison.

\begin{tabular}{lcc}
\hline Class (group) & Latent mean & $\begin{array}{c}\text { Groups with significantly } \\
\text { smaller factor mean }\end{array}$ \\
\hline SSQ2 & 0.182 & - \\
DBQ & 0.000 & - \\
SSQ1 & -0.006 & - \\
\hline
\end{tabular}




\subsection{Tradition and Conformity}

Notation:

DBQ: 1, SSQ1: 2; and SSQ2: 3.

Non-equivalent parameters are presented in brackets.

Loadings

Trad1 1 (2) 3

Trad2 12 (3)

Conf1 123

Conf2 123

Intercepts/thresholds

Trad1 12 (3)

Trad2 1 (2) 3

Conf1 123

Conf2 123

Table A2. Factor mean comparison for tradition.

\begin{tabular}{lcc}
\hline Class (group) & Mean & $\begin{array}{c}\text { Groups with significantly } \\
\text { smaller factor mean }\end{array}$ \\
\hline SSQ2 & 0.000 & SSQ1 \\
DBQ & -0.229 & SSQ1 \\
SSQ1 & -1.374 & - \\
\hline
\end{tabular}

Table A3. Factor mean comparison for conformity.

\begin{tabular}{lcc}
\hline Class (group) & Mean & $\begin{array}{c}\text { Groups with significantly } \\
\text { smaller factor mean }\end{array}$ \\
\hline DBQ & 0.327 & SSQ1 \\
SSQ2 & 0.000 & - \\
SSQ1 & -0.071 & - \\
\hline
\end{tabular}

\section{References}

Aichholzer, J., and E. Zeglovits. 2015. "Balancierte Kurzskala autoritärer Einstellungen (B-RWA-6).” Zusammenstellung sozialwissenschaftlicher Items und Skalen (ZIS). DOI: https://doi.org/10.6102/zis239.

Altemeyer, B. 1981. Right-Wing Authoritarianism. Winnipeg: University of Manitoba Press.

Bassili, J.N., and B.S. Scott. 1996. "Response Latency as a Signal to Question Problems in Survey Research.” Public Opinion Quarterly 60(3): 390-399. DOI: https://org/doi. 10.1086/297760.

Beauducel, A., and W.W. Wittmann. 2005. "Simulation Study on Fit Indexes in CFA Based on Data With Slightly Distorted Simple Structure." Structural Equation 
Modeling: A Multidisciplinary Journal 12(1): 41-75. DOI: https://doi.org/10.1207/ s15328007sem1201_3.

Beierlein, C., F. Asbrock, M. Kauff, and P. Schmidt. 2014. Die Kurzskala Autoritarismus (KSA-3): Ein ökonomisches Messinstrument zur Erfassung dreier Subdimensionen autoritärer Einstellungen. (GESIS-Working Papers, 2014/35). Mannheim: GESIS Leibnitz-Institut für Sozialwissenschaften. Available at: http://www.gesis.org/ fileadmin/kurzskalen/working_papers/KSA3_WorkingPapers_2014-35.pdf (accessed February 2019).

Bless, H., G. Bohner, T. Hild, and N. Schwarz. 1992. "Asking Difficult Questions: Task Complexity Increases the Impact of Response Alternatives." European Journal of Social Psychology 22(3): 309-312. DOI: https://doi.org/10.1002/ejsp. 2420220309.

Borgers, N., and J. Hox. 2001. "Item Nonresponse in Questionnaire Research with Children." Journal of Official Statistics 17(2): 321-335. Available at: https://www. scb.se/contentassets/ca21efb41fee47d293bbee 5 bf 7 be $7 \mathrm{fb} 3 /$ item-nonresponse-in-questionnaire-research-with-children.pdf (accessed September 2020).

Bradburn, N.M., S. Sudman, and B. Wansink. 2004. Asking Questions: The Definitive Guide to Questionnaire Design: For Market Research, Political Polls, and Social and Health Questionnaires. San Francisco: Jossey-Bass.

Campbell, J.C., D.W. Webster, and N. Glass. 2009. "The Danger Assessment: Validation of a Lethality Risk Assessment Instrument for Intimate Partner Femicide." Journal of Interpersonal Violence 24(4): 653-674. DOI: https://doi.org/10.1177/08862605083doi. 17180.

Chen, F.F. 2007. "Sensitivity of Goodness of Fit Indexes to Lack of Measurement Invariance." Structural Equation Modeling: A Multidisciplinary Journal 14(3): 464-504. DOI: https://doi.org/10.1080/10705510701301834.

Cohen, J. 1992. “A Power Primer.” Psychological Bulletin 112(1): 155-159. DOI: https:// doi.org/10.1037/0033-2909.112.1.155.

Dillman, D.A., J.D. Smyth, and L.M. Christian. 2014. Internet, Mail, and Mixed-Mode Surveys: The Tailored Design Method. Hoboken, NJ: Wiley.

ESS, European Social Survey. 2014. ESS Round 7 Source Questionnaire. London: ESS ERIC Headquarters, Centre for Comparative Social Surveys, City University London. Available at: https://www.europeansocialsurvey.org/docs/round7/fieldwork/source/ESS7_source_main_questionnaire.pdf (accessed February 2019).

Fowler, F.J., Jr.. 1992. "How Unclear Terms Affect Survey Data." Public Opinion Quarterly 56(2): 218-231. DOI: https://doi.org/10.1086/269312.

Gemenis, K. 2013. "Estimating Parties' Policy Positions through Voting Advice Applications. Some Methodological Considerations.” Acta Politica 48(3): 268-295. DOI: https://doi.org/10.1057/ap. 2012.36.

Graesser, A.C. 2006. "Question Understanding Aid (QUAID): A Web Facility that Tests Question Comprehensibility.” Public Opinion Quarterly 70(1): 3-22. DOI: https://doi. org/10.1093/poq/nfj012.

Grant Levy, S. 2019. "Deconstructing a Double-Barreled Alternative: Evolution and Creationism." Psychological Reports 122(5): 1995-2004. DOI: https://doi.org/10. 1177/0033294118795145. 
Groves, R.M., F.J. Fowler, Jr., M.P. Cooper, J.M. Lepkowski, E. Singer, and R. Tourangeau. 2009. Survey Methodology, (2nd ed.). Oxford: Wiley.

Hox, J.J., E.D. de Leeuw, and E.A.O. Zijlmans. 2015. "Measurement Equivalence in Mixed Mode Surveys.” Frontiers in Psychology 6: 87. DOI: https://doi.org/10.3389/fpsyg.2015.00087.

Hu, L., and P.M. Bentler. 1999. "Cutoff Criteria for Fit Indexes in Covariance Structure Analysis: Conventional Criteria Versus New Alternatives." Structural Equation Modeling: A Multidisciplinary Journal 6(1): 1-55. DOI: https://doi.org/10.1080/ 10705519909540118.

Kane, M.T. 2013. "Validating the Interpretations and Uses of Test Scores." Journal of Educational Measurement 50(1): 1-73. DOI: https://doi.org/10.1111/jedm.12000.

Kay, P., and C.J. Fillmore. 1999. "Grammatical Constructions and Linguistic Generalizations: The What's X Doing Y? Construction." Language 75(1): 1-31. DOI: https://doi.org/10.2307/417472.

Krosnick, J.A. 1991. "Response Strategies for Coping with the Cognitive Demands of Attitude Measures in Surveys." Applied Cognitive Psychology 5(3): 213-216. DOI: https://doi.org/10.1002/acp. 2350050305.

Krosnick, J.A., and S. Presser. 2009. "Question and Questionnaire Design.” In Handbook of Survey Research, edited by J.D. Wright and P.V. Marsden., (2nd ed.) (pp. 263-313). San Diego, CA: Elsevier.

Le Payne, S. 1951. The Art of Asking Questions. Princeton, NJ: Princeton University Press. Lenzner, T., C. Neuert, P. Hadler, A. Stiegler, C. Beitz, R. Schmidt, Z. Umuc, N. Reisepatt, S. Andrea, and N. Menold. 2017. "Krankheitswissen und Informationsbedarfe - Diabetes mellitus. Fragebogen für Personen mit Diabetes." Available at: http:// pretest.gesis.org/pdf/ProjektBericht/Projektbericht-17-03.pdf (accessed February 2019)

Lenzner, T., L. Kaczmirek, and A. Lenzner. 2010. "Cognitive Burden of Survey Questions and Response Times: A Psycholinguistic Experiment.” Applied Cognitive Psychology 24(7): 1003-1020. DOI: https://doi.org/10.1002/acp. 1602.

Lord, F.M., and M.R. Novick. 1968. Statistical Theories of Mental Test Scores. Reading: Addison-Wesley.

Menold, N., and T. Raykov. 2015. "Can Reliability of Multiple Component Measuring Instruments Depend on Response Option Presentation Mode?" Educational and Psychological Measurement 76(3): 454-569. DOI: https://doi.org/10.1177/00131644 15593602.

Meredith, W. 1993. "Measurement Invariance, Factor Analysis and Factorial Invariance." Psychometrika 58(4): 525-543. DOI: https://doi.org/10.1007/BF02294825.

Messick, S. 1989. "Meaning and Values in Test Validation: The Science and Ethics of Assessment.” Educational Researcher 18(2): 5-11. DOI: https://doi.org/10.3102/0013 189X018002005.

Muthén, B.O. 2002. "Beyond SEM: General latent variable modeling." Behaviormetrika 29(1): 81-117. DOI: https://doi.org/10.2333/bhmk.29.81.

Muthén, B.O., and T. Asparouhov. 2014. "IRT Studies of Many Groups: The Alignment Method." Frontiers in Psychology 5,978. DOI: https://doi.org/10.3389/fpsyg.2014. 00978 . 
Muthén, L.K., and B.O. Muthén. 2017. Mplus User's Guide. Los Angeles, CA: Muthén \& Muthén.

Olson, K. 2008. "Double Barreled Question." In Encyclopedia of Survey Research Methods, edited by P.J. Lavrakas. (pp. 209-211). Thousand Oaks, CA: Sage Publications. DOI: https://doi.org/10.4135/9781412963947.n145.

Oppenheim, A.N. 1992. Questionnaire Design, Interviewing, and Attitude Measurement. New York City: St. Martin's Press.

Raykov, T., and G.A. Marcoulides. 2011. Introduction to Psychometric Theory. New York: Taylor \& Francis.

Raykov, T. 2012. "Scale Construction and Development Using Structural Equation Modeling." In Handbook of Structural Equation Modeling, edited by R.H. Hoyle. (pp. 472-492). New York: The Guilford Press.

Raykov, T., N. Menold, and G.A. Marcoulides. 2018. "Studying Latent Criterion Validity for Complex Structure Measuring Instruments Using Latent Variable Modeling." Educational and Psychological Measurement 78(5): 905-917. DOI: https://doi.org/ 10.1177/0013164417698017.

Reise, S. 2012. "The rediscovery of bifactor measurement models." Multivariate Behavioral Research 47: 667-696. DOI: https://doi.org/10.1080/00273171.2012. 715555.

Schaeffer, N.C., and J. Dykema. 2011. "Questions for Surveys: Current Trends and Future Directions.” Public Opinion Quarterly 75(5): 909-961. DOI: https://doi.org/10.1093/$\mathrm{poq} / \mathrm{nfr} 048$.

Schwartz, S.H., B. Breyer, and D. Danner. 2015. "Human Values Scale (ESS)." Zusammenstellung sozialwissenschaftlicher Items und Skalen (ZIS). DOI: https://doi. org/10.6102/zis234.

Schwartz, S.H. 2003. “A Proposal for Measuring Value Orientations across Nations.” In Questionnaire Development Package of the European Social Survey. Available at: http://www.europeansocialsurvey.org/docs/methodology/core_ess_questionnaire/ ESS_core_questionnaire_human_values.pdf (accessed February 2019).

Stafford, L. 2011. "Measuring relationship maintenance behaviors. Critique and development of the revised relationship maintenance behavior scale." Journal of Social and Personal Relationships 28(2): 278-303. DOI: https://doi.org/10.1177/ 0265407510378125.

Tourangeau, R., L.J. Rips, and K.A. Rasinski. 2000. The Psychology of Survey Response. Cambridge: Cambridge University Press.

Vettehen, P.G.H., and L.B. van Snippenburg. 2002. "Measuring Motivations for Media Exposure: A Thesis.” Quality and Quantity 36(3): 259-276. DOI: https://doi.org/10. 1023/A:1016076505379.

Williams, R.T., A.W. Heinemann, R.K. Bode, C.S. Wilson, J.R. Fann, and D.G. Tate. 2009. "Improving Measurement Properties of the Patient Health Questionnaire-9 with Rating Scale Analysis.” Rehabilitation Psychology 54(2): 198-203. DOI: https://doi. org/10.1037/a0015529.

Yan, T., and R. Tourangeau. 2008. "Fast times and easy questions: the effects of age, experience and question complexity on web survey response times." Applied Cognitive Psychology 22(1): 51-68. DOI: https://doi.org/10.1002/acp. 1331. 
Yorkston, K.M., C.R. Baylor, J. Dietz, B.J. Dudgeon, T. Eadie, R.M. Miller, and D. Amtmann. 2008. "Developing a Scale of Communicative Participation: A Cognitive Interviewing Study." Disability and Rehabilitation 30(6): 425-433. DOI: https://doi. org/10.1080/09638280701625328.

Received March 2019

Revised June 2020

Accepted August 2020 